\title{
The art therapy large group as a teaching method for the institutional and political aspects of professional training
}

\author{
Sally E. Skaife MA Dip Psychotherapy ATC, AsT(A)* \& \\ Kevin Jones MA Dip Psychotherapy (IPSS UKCP) AsT(A)
}

Lecturer, Art Psychotherapy, Professional and Community Education (PACE), Goldsmiths, University of London, Deptford Town Hall,

New Cross Road, London SE 14 6NW

Keywords

art, large group, political, professional, therapy, training
${ }^{*}$ Correspondence author. Tel: 02079197598 fax: 0207919 7236; e-mail: s.skaife@gold.ac.uk

\section{Abstract}

This paper discusses a unique experiential teaching method in the context of training for art psychotherapists and raises issues relevant to teaching for all workers in health and social care. The art therapy large experiential group of all the students and all the staff $(80+)$, which is held six times a year on the 2-year full-time/3-year part-time programme, is identified with three educational components: learning about art therapy processes, learning about the educational process of becoming a professional, and learning about institutional and political issues relevant for the work-place.

This educational method engages the unconscious dynamics of both students and staff and brings this together, through creative activity, with a critical engagement in social and political issues. The group has implications for all health workers in its attention to non-verbal communication, activity as a means to learning and agency in institutional issues in the work-place. The paper brings together a case example in which students were able to process the impact of a nationwide, union strike in the university, with relevant literature from large group theory, small art therapy group theory and performance art. Discussion is given to the process by which the art therapy large group meets its learning objectives.

\section{Introduction}

This paper describes an innovative teaching method for trainee art psychotherapists at Goldsmiths, University of London. The paper looks at how an experiential art therapy large group of staff and students, that is 80 plus people, can be an effective method of teaching about art therapy processes, and the generic skills in health and social care that are relevant to all health and social care professions. It does this through engaging students in a psychodynamic process held within an educational frame. Its conception as a group standing at the interface between college and the wider community 
and the smaller groups in the programme and clinical work, enables learning to pass from global issues to the minutiae of clinical practice and back. The art therapy large group (ATLG) raises political issues general to all health and social care professions.

The theoretical base of the ATLG raises political issues from the start. In it, the individual is understood as inseparable from the social group, a contrary position to the notion of individual pathology which is the current focus of mental health provision. Similarly, art is understood as arising from the dynamic relation between art performers and involved spectators, instead of originating from an individual inner self. The coming together of all the students at their different stages of learning and from their different countries of origin to make art, raises political issues, such as: relating with others who are different, the significance of active agency, and what becoming a professional health worker entails. The ATLG is also a very good way of bringing issues in art therapy theory and practice to students' attention as it magnifies concerns present in one-to-one and small group art therapy.

There is a small literature on verbal large groups which describes its origins in a military hospital during the war, and its continuation in psychiatric services in the 1970s and 1980s. Although the large group has largely disappeared in the National Health Service, it is now an accepted part of many group analysis training events and conferences (De Mare, Piper \& Thompson 1991; Trampuz 1993; Blackwell 2000; Pines 2003).

Although most of the writers on large groups draw from their experiences of large groups in educational or experiential settings, there is little in the literature that addresses educational method. There is no literature of which we are aware on large art therapy groups.

We will first describe our method and then go on to introduce the Goldsmiths' ATLG and the literature which contextualizes it on verbal large group theory, art therapy group theory and performance art. Following this we will present a case example, a single session of the group, then draw out issues relevant to meeting the learning objectives and relate these to relevant literature.

\section{Method}

Our research method is action-based research (Reason 1994), a method which mirrors the same principles as that of the art therapy training as a whole, as well as the clinical work that we are teaching about. Macleod (2001) describes the following key principles of action-based research: learning is irrevocably linked with action, understanding is generated through practical activity, knowledge is intrinsically collective and relational, and true knowing involves embracing the subjective dimension of experience. Creating knowledge is a cyclical process, reflecting on experience, generating hypotheses, testing hypotheses in action, reflecting on the experience produced by this practical action, and challenging these insights with others. The goal is objective subjectivity and disciplined reflexivity.

Our method had involved cycles of reading, reflecting on the impact of the insights gained as they apply to an understanding of the activities of the large group, discussion with the staff team, lecturing to students on the large group, writing and reflecting on our written texts and relating findings to the experience of the large group. The data we produced were our written process notes following the large group described. We amalgamated our two accounts of the session described to draw up one coherent story.

We have analysed our case material with ideas from the following literature: art therapy group theory (Waller 1993; Skaife \& Huet 1998; McNeilly 2006; S. Skaife, University of London, London, in prep.), large and small group analytic theory (Kreeger 1975; De Mare et al. 1991; Schneider \& Weinberg 2003), and various texts on performance art (Goldberg 1979; Etchells 1998; Schechner 2002). We will now introduce the ATLG at Goldsmiths, University of London.

\section{The art therapy large group at Goldsmiths}

\section{Context in the programme}

The ATLG takes place in the context of the Masters in Art Psychotherapy, a training programme which 
harnesses students' previous experience of art and draws on psychoanalytic and group analytic theory. It is structured and conceived according to systems theory (Agazarian \& Peter 1981). The programme engages experiential, self-directed and didactic teaching with an emphasis on learning through doing (Dies 1980; Hobbs 1992). There is continuous assessment throughout the course on placement and in teaching sessions, as well as of academic essays. Students' engagement in the large group is formally assessed by their ability to write, and therefore think reflectively about their experience in the group in a written assessment at the end of each year.

\section{Structure}

Students are first introduced to the ATLG in a written explanation with aims and objectives in the student handbook, and in introductory teaching sessions at the start of the programme. The group meets twice a term for an hour and a half per session, giving six sessions per academic year in all. Dry art materials, crayons, pens, paper of various sorts, string, fabric, are put out in large crates in the centre of the empty space in the middle of the circle of chairs one or two deep depending on the size of the room. As in group analysis, the group are encouraged to express themselves freely while respecting each others' space and well-being. Unlike in group analysis, however, moving about the room and non-verbal communication is part of the activity of the group. The objectives of the group are spoken to at the start of the first session of each year. As in the other groups on the programme, the students are asked to stay in the room during the whole of the session and to attend regularly and punctually.

\section{The facilitators}

The group is facilitated by the total staff team, currently that is nine members. Staff understand their role to be threefold: facilitating the objectives, keeping the boundaries and role modelling. The staff meet for an extended post-group following each session and, where possible, the staff also meet before the group. During these staff group sessions, free floating dialogue is used as a means to elicit unconscious concerns among the learning community of the programme.

\section{The history}

The implementation of the ATLG at Goldsmiths was linked to the fact that some of the staff had trained in group analysis and had also participated in large groups in the National Health Service. When circumstances arose to reconsider the input of verbal psychotherapy groups in the course, we decided to offer instead a model of group work which integrated with the whole course model. Choosing the ATLG, this method reflected a move in the historical and hierarchical relations between verbal psychotherapy and art psychotherapy on the course. We looked to the large group literature and to small art therapy group literature for a theoretical base. We found that the mode of art work which seemed to flourish in the ATLG was performance art, so we looked to its literature to develop our thinking.

\section{Context in the literature}

\section{Large group theory}

De Mare et al. (1991) emphasize the social and political possibilities of the large group. Comparing the large group to small groups and one-to-one psychotherapy, they talk about engaging dialogue in place of the group association and free association that are utilized in small groups and psychoanalysis, respectively. Whereas in the small group, members work on becoming aware of their feelings in relation to their roles in the family, in the large group they struggle to think about the social issues that determine family life. The goal of thinking together through dialogue attempts to galvanize and transform unconscious primitive feelings into a sensitive thinking apparatus (De Mare et al. 1991). Unlike in structured forums for political debate and institutional decision-making, all voices are given equal weight which levels out hierarchy resulting in strong group cohesion, inclusiveness and true democracy. 
De Mare et al. talk about the large group as offering the possibility for a study of processes through the study of a microculture. Certainly, the large verbal group is an arena for students to learn about the situations that they can find themselves in on placement and later in the work-place.

\section{Art therapy group literature}

There have been various different models for using art in therapy groups over the years that are described in the literature with the following names: open studios (Thomson 1989; Luzzato 1997; Moon 2002), theme-based groups (Liebmann 1986), group analytic art therapy (McNeilly 2006), group interactive art therapy (Waller 1993), art psychotherapy groups (Skaife \& Huet 1998). These can be understood as determined by the institutional and historical context in which they have developed. However, in distinguishing the models by the relationship between talking and art making in them, one becomes aware of a hierarchy between cognitive and perceptual processes which is then associated with client categories (S. Skaife, University of London, London, in prep.).

The problems in the relationship between art and talking in art therapy are magnified in the large group, which because of its size shows up the performative aspect of art making, making the literature on performance art relevant (Schechner 2003).

\section{Performance art}

Performance art reflects a number of ethical and political preoccupations relevant to a variety of health professionals. In performance art, meaning arises in the interaction between performer, performance and spectator, and the emphasis is on this process of interaction rather than the production of an art object. This involves a deliberate ethical stance which aims to change the audience/artist relationship from one of passive spectatorship and consumption, to active participation through witness or action (Etchells 1998).

The emphasis is on the process of the performance, with the accent on pleasure and play rather than the aesthetic qualities of the art object, and indeed, performance is not dependent on an art object being created (Kaye 2000). Performance art can potentially oppose the hierarchical divisions between cognition and perception in western society which are reflected in art therapy group practice.

Through participation in the large group as either performer or spectator, students learn about the performances that take place on a smaller scale in both the small group and the individual setting of art therapy and their relationship to making art with clients. The meaning of a performance work is also specific to the particular site in which it takes place, as is illustrated in the art therapy group example.

We will now go on to give an example of a single session of the ATLG.

\section{The case example}

Before and during the session described, art therapy staff were involved in a national union dispute over pay and along with other university lecturers were not marking work that lead to progression on their courses or the award of a final mark leading to graduation. The dispute raised general issues of low university pay and the marketization of public services that would adversely affect the quality of art psychotherapy education and the wider profession in the future. The strike highlighted a broader struggle over the profession, its status and recognition within society.

This session, which was the last in the academic year, took place in the main college hall for the first time, an extremely large room which actually dwarfed the $80+$ members of the large group. There was a platform, and props - a lectern and tiered seating on the platform. Among other things, the hall was also used for graduation ceremonies.

In the pre-group staff meeting, there were differences acknowledged between staff over another financial event, the reduction of hours for those on short-term contracts. The subject of persecutors and victims arose and we left for the group holding these difficult exchanges.

There was a flurry of art making and activity in the first 45 minutes. A number of figures had been made including a large, flat paper cut-out figure, which lay on the floor and a figure sculpture made 
from a lectern draped in clothes. A female student began to make rolls of paper and after she had laid them out on the tiered benches on the stage, they looked like graduation certificates. A female staff member moved a chair into the centre of the stage. The paper rolls were now taken up and put by the paper cut-out and then later given to the chair. The level of noise in the group was now rising and there seemed to be a lot of activity around the room. Another female student was rolling up the edges of sheets of paper so that they looked like water lilies and then throwing them into the circle. A student made a placard with the message 'The End is Neigh'. She walked very fast around the inside of the circle, holding the placard aloft and then went into the centre of the circle where she knelt bent over double with her face hidden, for some time (see Fig. 1).

Kevin, feeling increasingly concerned about the student in the centre expressed his concern and discomfort and linked this to the 'Neigh', which he thought could be construed as the end is 'Nay', the course will not finish because no one can graduate. There was silence and then more activity, and after a while, the student in the centre sat up and said that the placard did refer to the end of the year, but not to the possibility of not finishing. Some students then complained about the silence being broken. When another male member of staff interpreted these comments, an argument started between him and the complaining students. The argument developed like a boxing match that was both aggressive and humorous, a performance which seemed to enact tensions in the group.

Someone kept trying to pile up the water lilies which would then fall down, others found this very annoying. It was a painful performance to watch. Sally began to feel extremely uncomfortable unable to speak or to act.

Towards the end, a student took the lectern figure apart and laid it down on the floor. He said that he was leaving this year and that he would miss the group. A staff member said that he would miss his contributions to the group. Other students asked if the staff member would miss people who had not made any comments. In the meantime, someone had put a shawl over the lectern figure now lying on the floor. These acts seemed to visibly resolve the charged atmosphere in the room.

In the staff post-group, some had enjoyed the large space in the main hall, the sense of being at the centre of the college, and there was a general excitement and pleasure in the extended use of the art materials. Divisions suddenly erupted again around the question of whether or not we had needed to verbalize in the group. Might not feelings have been contained in the artwork and performance? The split quickly became gendered and the polarized feelings from the pre-group and the conflict in the large group emerged again. Like the boxing match in the group, this seemed to be a necessary process,

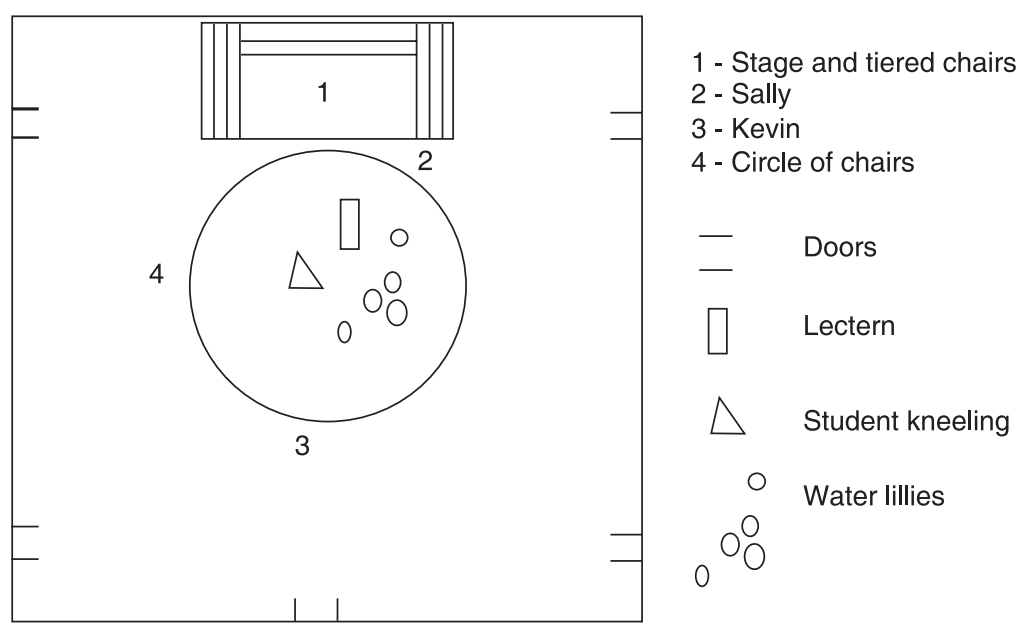

Fig. 1 Art therapy large group. Layout of ATLG in main hall of college at midpoint of case example. 
holding the very uncomfortable dynamics with which we were all involved.

The case material in this paper is also found in Jones and Skaife (2009).

\section{Theoretical issues}

We will now use this example and ideas in the relevant literature to consider some processes in the ATLG which facilitate the learning objectives. To reiterate, these are learning about processes in art therapy, understanding what is involved in becoming a professional art therapist, and becoming aware of institutional and political issues. We will look at are the transformational process, 'making a mark' and 'finding a voice', becoming a professional, art therapy processes and the learning process. Finally, we will discuss the role of the facilitators.

\section{The transformational process}

At the start of the session described, there was a lot of activity with several simultaneous performances expressing issues around power and unbearable tension as symbolized by the tower of water lilies which would not stand up. By the end of the group session, there had been a change and a sense of connection had been achieved.

As in all groups which engage a psychodynamic process, a transformational process had taken place through the resolution of conflict (Agazarian 2003). In the large group, conflict is created by the feelings engendered by its sheer size which frustrates the need for intimacy which might itself ameliorate the disorientating feelings. Hopper (2003) describes members feeling as though they are lost or swallowed by an impersonal force. As a result, hatred of others arises and the group is likely to form subgroups which enable them to feel less isolated (De Mare et al. 1991). In the session described, conflict erupted with a battle between the students and some staff members over whether or not it was appropriate to interpret the activity going on in the group. The staff members themselves formed two antagonistic camps based on gender as was later discovered in the post-group. The theme of this ATLG session appeared to be about power.
In the ATLG, power issues often get played out between the subgroups: the performing group, the group making individual art works on the floor or sitting in the circle and the spectating group. The possibility of moving between these groups sharpens up a focus on the different experiences, in particular about the different sorts of power. Taking a dramatic action in the group can be felt to empower some and silence other group members, the power to watch and criticize is another sort of power. Staying with the anxiety, frustration and envy generated in this setting gives students an opportunity to learn to work with difference in the wider world; and in mirroring sibling rivalry, these processes can be helpful in understanding relations in staff teams.

Skynner (1975) talks of a process of group maturation in which the group survives the splitting and projections of an early phase and goes onto the remarkable creativity that is possible in the depressive phase. This was illustrated in the action of the students with the paper cut-out and lectern figures. The laying down of the lectern figure by the male student and the female student draping the paper cut-out figure put the conflicts around power which threatened the group to rest. The performance seemed to represent the power of the group itself over power being invested in the subgroup of the staff. This resolution allowed an ordinary face-to-face acknowledgement of leaving the course to be expressed. Holding onto the importance of dialogue across difference allowed everyone to stay with the difficult tensions and so to process the external conflict.

\section{Making a mark, finding a voice}

Anxiety provoked by the group and the consequent sense of fragmentation in the individual gives rise to threatening feelings in which thinking can feel impossible. The issue at stake appears to be one of 'annihilation or survival' (Turquet 1975). The size of the group seems to make it hard to conceptualize it, and then to make any action in it seem impossible or pointless (Kreeger 1975; Main 1975; Turquet 1975; Thompson 1999) Through their 'making a mark' and 'finding a voice', students in the ATLG struggle with feelings of alienation and fragmentation and 
with how to find a place for themselves in the group. Their actions in art or talk, recognized by others in the group, allow them a sense of belonging in a community. The boundary of the arena, which creates a space like an empty page, allows for a response to an action or visual statement to be observed, noted and reflected on. Each time though, students are faced with the risk of feelings of alienation or pointlessness in the group, the challenge of surviving the group, and the option to make a mark on it. Whether or not action is taken is therefore about agency and thus becomes political. Passing through this process can enable students to learn about both surviving institutions and finding themselves an effective role within the institutions in which they will practice. De Mare et al. (1991) think that the number of individuals who can speak and be heard by such a large number, is itself the goal as it is this that creates 'Koinoia', a community or fellowship.

The ATLG has students from all around the world, from different class backgrounds, from different year groups, as well as the staff student difference. These differences apparent in small groups can lead to feelings of paranoia and stranger anxiety in the large group (Frosh 2008). However, the possibility of addressing them in this large forum where 'everyone' is present allows their visibility making it possible to look at them in a more detailed way in the smaller arenas of the supervision group and experiential group.

\section{Becoming a professional art therapist}

It was notable that it was the finalist students who engaged in the play around graduation, while the mid-course students were concerned with staff power and with frustration in their play with the lectern figures and the water lilies. The session was the end one of the year, and became a forum in which this passing through could be acknowledged together by staff and students, not by a party (that came later) but in a way which allowed existential issues about life and death to be expressed and thought about. The student who knelt with her sign which prophesied death - 'the end is nigh' (which is what she had meant to write) enacted a death in her stillness in the centre of the room. Such activity allows students to consider their own action in relation to their position in the life cycle of the programme and in their personal lives.

At Goldsmiths, the large group is the one arena in which all the art therapy students meet together. The rhythm of the academic year marks beginnings and endings clearly and the arena of the large group is the life space in which cohorts join, work and play and then leave in batches, full-timers before parttimers. Students at the end of the course have understood and integrated things that students at the beginning of the course are just being introduced to. Although sometimes painful, it is possible for students, through revisiting the questions with which they started out, and seeing what has happened to themselves in their learning process, to witness the process over time of what learning to become an art therapist actually means.

De Mare et al. talk about dialogue and they mean verbal intercourse, where does this position art making? We can extend dialogue to include art and performance and other non-verbal communication although the question remains as to whether the purpose of the art/performance is to facilitate verbal dialogue or whether it is enough in itself as dialogue, as was apparent in the case example.

\section{Art therapy process}

In the case example, the sense of threat posed by the ATLG experience itself was amplified by the strike action and produced a flurry of individual activity, subgroupings, a proliferation of images and objects and a fracturing of the circle, culminating in an escalation of movement and rising noise. The writing on the placard highlighted the disjunction between the visual and the verbal and acted as a hinge point for the transition from visual to verbal representation, which brought out an enactment of conflict. The verbal conflict turned into a performance.

The relationship between the art and verbal language or between the perceptual and the cognitive is historically hierarchical and mirrors divisions in race, class and gender which is reflected in the low status given to the perceptual and 
imaginative in treatments for psychiatric conditions (Skaife 2008). Shifts between talking and art making thus involve students in an active engagement with issues around power. It was significant that the female staff appeared involved in the non-verbal performances and male staff with the verbal. This is not always the case in the large group but this subgrouping could be understood as an enactment of power divisions.

In the ATLG, everything happens simultaneously and it is impossible to see all that is made or to hear everything that is said. This requires a different sort of attention to that in individual or small group therapy. The tensions between talking, art making and looking become exaggerated as people find equal frustration and satisfaction in both finding meaning through talking and in art making.

The larger physical space necessary for the ATLG poses the room as an interactive stage, and the art materials and people's bodies, as performers or spectators, become art works. The relationships between the student and their art work, the art and the group all become mixed, inviting new ways to consider the role of art in therapy. If we understand all activity in the group as interrelated performances and apply this to the small group, it helps confront the issue of art and the perceptual being thought of only as a bridge to the more important verbal interaction.

\section{The learning process}

The experiential containment in the ATLG of the mixed feelings of anger, envy and sympathy about the strike allowed thinking and learning in other more didactic teaching contexts on the course. Discussion in business meetings connected students to support from the National Union of Students and a new sense of the place of the course in the wider college. Working with the staff, some students published their own account of the strike in the newsletter of the professional association. This learning may also have empowered students to organize among themselves to mount a challenge to the college in a different context the following year.

Learning in the ATLG is understood to happen through its relationship with other groups within the programme and its relationship to even larger groups beyond the programme (Agazarian 2003). As such, it is a subgroup itself. Learning is understood to take place at the interface between the groups. The permeable boundaries between different subgroups, when stable, allow in new material which is worked through to enable the new material to be integrated. Learning then passes from group to group. Just as the ATLG magnifies processes in small groups, learning from the ATLG passes into the smaller groups in the training. Discussion about what has happened in the ATLG is related to institutional issues that are brought into supervision groups. Similarly, performance aspects of the ATLG affect the way students view art practice in the small experiential groups, allowing students to consider their art work with clients differently and explore issues that have arisen in relation to the large group dynamics.

\section{The role of the facilitators}

In order to facilitate the learning objectives of the group, the staff must keep the boundary of the space, ensure that there are no intrusions by people not meant to be in the group, keep the time and take care that no one individual is 'in trouble' without recognition. Kevin broke the verbal silence because he was concerned about the student with the placard. These basic functions of the art therapist enable the group to take on intensity, and a sense of play and theatre. At the same time, staff need to be more than just keepers of the space. They also need to role model a willingness to allow the group to move them, to have faith in the process which they are teaching the students. Their engagement with art materials allows them to be in communication with the non-verbal aspects of the group. Some staff involved themselves in the students' play around the figures of power. Thus staff in the ATLG act both as performers and spectators in the group, making sure a suitable balance of roles, keeper or observer of the space and actor in it, is distributed among them at any one time. However, the staff's engagement in the group must always be in the service of the groups' objectives despite the fact that they too will experience the 'annihilation and survival' dynamic (Turquet 1975). 
Main (1975) and Thompson (1999) comment that the key thing is to stay with the anxieties and learn to communicate from within them. They say that it is helpful if facilitators speak from their own personal experience of being in the group, rather than make interpretations that try to summarize the whole group experience as these tend to amplify a sense of observer and observed, increasing feelings of fragmentation. The staff member who attempted to interpret the group's activity then involved himself in a verbal contest with students thus moving from a figure of power to a performer.

The ATLG is the only place that all the staff work together as a team with all the students. This allows students to see that staff have differences in approach and gives students confidence in their own capacity for team work and to find their own way of working. As the staff work differently in the ATLG as compared with the small art therapy experiential groups, students can learn about different ways of working in different contexts.

\section{Discussion}

This paper is part of the culmination of the first stage of our research process. There have been some limitations which we hope to address in the next stage. For example, there are no images, as for reasons of confidentiality no photography is allowed in the group at present. Our account of the session is limited, as we have had to bear student confidentiality in mind; it also only represents the personal viewpoints of two authors taken from two particular places in the group.

We are now beginning the next cycle of action, learning and reflection and have introduced two lectures on the ATLG, the first giving a theoretical background, and the second using small focus groups to discuss student learning. We have also re-opened the debate on the use of photography to record the group. We now also meet with an outside consultant in the post-group following the ATLG.

Our next research project will pay particular attention to including the experience of other staff and students, visual documentation, the documentation of the interface between the ATLG and the smaller groups within the course and recording the ATLG over the course of a year.

\section{Conclusion}

The ATLG adds a new dimension to large groups as it introduces a focus on agency and creativity in the group. Although each profession might use their own medium, the ATLG introduces the potential of large groups for teaching about and working through institutional, political and social issues of practice, including the common dilemmas as health and social care professionals that we all face.

The ATLG shows that working with the power relations between students and teachers can be an important part of learning. It may seem most obviously suitable for arts/psychotherapy trainings but the focus on non-verbal process is relevant for all healthcare professionals when working with colleagues and clients. It may be that a one off or weekend ATLG experience, suitably modified to reflect particular circumstances, or a small group art therapy experience, may be helpful on other professional trainings.

The ATLG example shows how students gained a new understanding of their political agency and about the power of acting collectively to represent their interests, in a way that is effective and relevant to future activity in their professional organizations and trade unions.

\section{References}

Agazarian Y. (2003) Systems-centered Therapy for Groups. Guilford Press, London and New York. Agazarian Y. \& Peter R. (1981) The Visible and Invisible Group: Two Perspectives on Group Therapy and Group Process. Tavistock and Routledge, London.

Blackwell D. (2000) And everyone shall have a voice. Group Analysis 33, 19-20.

De Mare P., Piper R. \& Thompson S. (1991). Koinonia: From Hate through Dialogue to Culture in the large Group. Karnac, London.

Dies R.R. (1980) Current practice in the training of group psychotherapists. International Journal of Group Psychotherapy 30, 169-185. 
Etchells T. (1998) Valuable spaces. In: A Split Second of Paradise (eds N. Childs \& J. Walwin), p. 31. Rivers Oram Press, London and New York.

Frosh S. (2008) Desire, demand and psychotherapy: on large groups and neighbours. Psychotherapy and Politics International 6, 185-197. Published on-line: Sep 2008.

Goldberg R. (1979). Performance: Live art 1909 to the Present. Thames and Hudson, London.

Hobbs T. (ed.) (1992) Experiential Training, Practical Guidelines. Routledge, London.

Hopper E. (2003) Incohesion: aggregation/massification. The fourth basic assumption: the unconscious life of groups and group-like social systems. In: Building on Bion: Roots (eds R.M. Lipgar \& M. Pines), pp. 198-225. Jessica Kingsley, London.

Jones K. \& Skaife S. (2009) Under the cobblestones, the beach: the politics and possibilities of the art therapy large group. Psychotherapy and Politics International 7, $18-27$.

Kaye N. (2000) Site-specific Art. Routledge, London and New York.

Kreeger L. (ed.) (1975) The Large Group: Dynamics and Therapy. Karnac, London.

Liebmann M. (1986) Art Therapy for Groups: A Handbook of Themes, Games and Exercises. Croom-Helm, London and Sydney.

Luzzato P. (1997) Short term art therapy on the acute psychiatric ward: the open session as a psychodynamic development of the studio-based approach. Inscape 21 , 2-10.

Macleod J. (2001) Qualitative Research in Counselling and Psychotherapy. Sage, London.
Main, T. (1975) Some psychodynamics of large groups. In: The Large Group: Dynamics and Therapy (ed. L. Kreeger), pp. 57-86. Karnac, London.

McNeilly G. (2006) Group Analytic Art Therapy. Jessica Kingsley Publishers, London and Philadelphia.

Moon C.H. (2002) Studio Art Therapy: Cultivating the Artistic Identity in the Art Therapist. Jessica Kingsley Publishers, London.

Pines M. (2003) Large groups and culture. In: The Large Group Revisited (eds S. Schneider \& H. Weinberg), pp. 44-57. Jessica Kingsley, London.

Reason P. (1994) Participation in Human Inquiry. Sage Publications, London.

Schechner R. (2002) Performance Studies: An Introduction. Routledge, Oxon, UK.

Schneider S. \& Weinberg H. (eds) (2003) The Large Group Revisited. Jessica Kingsley, London.

Skaife S. \& Huet V. (eds) (1998) Art Psychotherapy Groups: Between Pictures and Words. Routledge, London.

Skynner R. (1975) The large group in training. In: The Large Group: Dynamics and Therapy (ed. L. Kreeger), pp. 227-251. Karnac, London.

Thompson M. (1989) On Art and Act Therapy: An Exploration. Virago Press, London.

Thompson S. (1999) The Group Context. Jessica Kingsley, London.

Trampuz D. (1993) The 'Yugoslav Crisis' reflected in the large group in the diploma course in Zagreb. Group Analysis 26, 183-188.

Turquet P. (1975) Threats to identity. In: The Large Group: Dynamics and Therapy (ed. L. Kreeger), pp. 87-144. Karnac, London.

Waller D. (1993) Group Interactive Art Therapy. Routledge, London. 